\title{
Alimentação de Bezerros Ruminantes com Dieta Líquida, Via Goteira Esofageana: Parâmetros Ruminais
}

\author{
Carlos de Sousa Lucci ${ }^{1}$, Renato Ranzini Rodrigues ${ }^{2}$, Paulo Henrique Mazza Rodrigues ${ }^{3}$
}

RESUMO - Efeitos de fornecer proteína texturizada de soja (PTS) na forma líquida, via goteira esofágica, ou na forma sólida, via concentrados, foram estudados em um delineamento quadrado latino 4 x 4, empregando quatro novilhos Holandeses providos de cânulas ruminais, pesando cerca de $100 \mathrm{~kg}$ cada, no início do experimento. Os tratamentos consistiram de níveis crescentes de PTS na forma líquida $(0,33,66$ e 100\%), oferecidos em mamadeiras, e níveis decrescentes de misturas concentradas, mantendo-se a mesma quantidade de nitrogênio em todas as dietas. Os subperíodos experimentais foram de 21 dias, sendo os primeiros 16 de adaptação às rações (feno de Cynodon dactilon, mistura concentrada e alimento líquido). Ensaio de digestibilidade in situ foi executado do dia 17 ao 20 , sendo os tempos de incubação de $0,1,5,3,6,12,24$ e 48 horas, para o farelo de soja e PTS, e 0, 6, 12, 24, 48h, 72 e 96 horas para o feno. Foram tomadas amostras de conteúdo ruminal para análise de volume e taxa de passagem de líquidos, e pH, no dia 21 às $0,1,3,6$, 12 e 24 horas. No dia 20, conteúdos ruminais foram coletados para análise de ácidos graxos voláteis (AGV) e N amoniacal às 0,2 , 4, 5 e $6 \mathrm{~h}$ após a primeira alimentação do dia. Foi observado aumento na taxa de passagem e turnover líquido com a diminuição do suplemento protéico na forma líquida. Não ocorreram efeitos da forma de alimentação nas concentrações dos totais de AGV ou nas suas porcentagens molares individuais, do mesmo modo que o pH não foi afetado. Não houve efeitos da forma de alimentação sobre a degradabilidade in situ da proteína e da matéria seca do farelo de soja e PTS, tampouco efeitos sobre a degradabilidade da matéria seca e fibra em detergente neutro do feno.

Palavras-chave: bezerros, digestibilidade ruminal, farelo de soja, proteína texturizada de soja

\section{Ruminant Calves Feeding with Liquid Diet, Through Esophageal Groove: Ruminal Parameters}

\begin{abstract}
Effects of feeding textured soy protein (TSP), in liquid form throught esophageal groove, or solid form throught concentrate meal, were studied in a 4 x 4 Latin-square change-over design, using four Holstein steers fitted with ruminal cannulas, averaging $100 \mathrm{~kg}$ live weight at the beginning of trial. Treatments consisted of increasing TSP levels in liquid form $(0,33,66$ and $100 \%)$ offered through nipple-pail, and decreasing levels in concentrate meal to keep the same amout of nitrogen in all diets. Twenty-one days sub periods were used, the first sexteen for diet adaptation (Cynodon dactilon hay, concentrate mixture and liquid feed). In situ degradability assay was runned from day 17 to 20, and incubation times were $0,1.5,3,6,12,24$ and 48hours for soybean meal and TSP, and 0, 6, 12, 24, 48, 72 and 96 hours for coastcross hay. Ruminal contents colections to analize liquid volume, passage rate, and $\mathrm{pH}$ were made at twentieth first day at $0 \mathrm{~h}, 1 \mathrm{~h}, 3 \mathrm{~h}, 6 \mathrm{~h}, 12 \mathrm{~h}$, and $24 \mathrm{~h}$. On twentieth day ruminal contents were colected to analyze volatile fatty acids (VFA) and ammonia nitrogen at $0,2 \mathrm{~h}, 3 \mathrm{~h}, 4 \mathrm{~h}, 5 \mathrm{~h}$ and $6 \mathrm{~h}$ after first feed. An increase in passage rate and ruminal turnover was observed as the liquid suplement protein amount decreased. There were no effects of feeding form in the total VFA concentrations or its individual molar percentages; also ruminal $\mathrm{pH}$ was not affected. There were no effects of feeding form upon in situ degradability of soybean meal and TSP dry matter (DM) and crude protein $(\mathrm{CP})$, as well as there were no effects in the degradability of Coast-Cross hay DM and neutral detergent fiber (NDF).
\end{abstract}

Key Words: calves, rumen degradability, soybean meal, textured soybean meal

\section{Introdução}

A suplementação protéica destinada a bezerros ruminantes pode ser feita nas formas sólida ou líquida. Na forma sólida, Petit et al. (1991) registraram melhor conversão alimentar, maior peso e rendimento de carcaça em bezerros recebendo proteína de farinha de peixe, de baixa degradabilidasde ruminal, compa- rados aos que receberam farelo de soja, de maior degradabilidade. O melhor desempenho dos terneiros seria resultante, principalmente, dos aminoácidos essenciais que chegam aos intestinos, pouco modificados pela flora ruminal em virtude da baixa degradabilidade da proteína (Swartz et al., 1991; Iriki et al. 1992; Sampath \& Sivaraman, 1986; Sampath et al., 1996). No caso de dietas com suplementação

\footnotetext{
1 Professor Titular USP, aposentado, Endereço atual: UNISA. E.mail: cslucci@uol.com.br

${ }^{2}$ Médico Veterinário, MS.

${ }^{3}$ Professor Assistente Doutor, USP
} 
protéica líquida, há formação da goteira esofágica (Ørskov et al., 1970) e, mesmo quando tal fato não ocorre, há passagem mais rápida dos nutrientes pelo rúmen, favorecendo a digestão da maior parte desses nutrientes no abomaso e intestino delgado. Portanto, o aproveitamento da proteína sobrepassante do rúmen parece ser fator preponderante na obtenção de melhores desempenhos. Contudo, não deve ser descuidada a fração degradável no rúmen que, decomposta até amônia, pode ser posteriormente transformada em proteína microbiana, propiciando a formação de todos os aminoácidos essenciais (Satter \& Slyter, 1974; McAllan \& Smith, 1983).

A variação na degradabilidade ruminal da proteína altera seu aproveitamento e modifica seu metabolismo, provocando variações no $\mathrm{pH}$ (Bowers et al., 1965; Albro et al., 1993), nas concentrações de ácidos graxos voláteis (AGV) e no $\mathrm{N}$ amoniacal do conteúdo do rúmen (Nocek et al., 1984; Abdelgadir et al., 1996).

Com o aumento da concentração de amônia no conteúdo ruminal, há maior digestibilidade da fibra no interior deste órgão (Hume et al., 1970; Mehrez et al., 1977; Rittenhouse et al., 1970; Van Gylswyk, 1970, McAllan \& Smith, 1983; Wiedmeier et al., 1983, Caton et al., 1988; Freeman et al., 1992). Lucci et al. (1989) detectaram maior desaparecimento ruminal para a fibra em detergente ácido (FDA), quando empregados $17 \%$ de proteína na dieta contra $13 \%$.

Os objetivos, no presente trabalho, foram analisar alterações no metabolismo geral do rúmen, quando a alimentação tem sua fonte de proteína fornecida na forma sólida ou líquida.

\section{Material e Métodos}

O experimento foi realizado na Faculdade de Medicina Veterinária e Zootecnia da Universidade de São Paulo, em Pirassununga - São Paulo. Foram utilizados quatro bezerros da raça Holandesa portadores de cânulas ruminais, com aproximadamente quatro meses de idade e $100 \mathrm{~kg}$ de peso vivo no início do experimento, durante o qual permaneceram em regime de estabulação completa. Adotou-se o delineamento experimental em Quadrado Latino 4 x 4 (Pimentel Gomes, 1985). Os tratamentos consistiram de níveis crescentes de proteína texturizada de soja na forma líquida (administrada em mamadeiras), combinados com níveis decrescentes da proteína na forma sólida (no concentrado), de modo que as quantidades do suplemento protéico fossem iguais e as dietas permanecessem isonitrogenadas: A: - 0\% de proteína na forma líquida, $100 \%$ no concentrado; B: - 33\% de proteína na forma líquida, $67 \%$ no concentrado; $\mathrm{C}$ : $-66 \%$ de proteína na forma líquida, $34 \%$ no concentrado; D: - 100\% de proteína na forma líquida, $0 \%$ no concentrado.

Como fonte de proteína, utilizou-se a proteína texturizada de soja (PTS), que, para administração na forma líquida, foi dissolvida em 2 litros de água morna $\left(32^{\circ} \mathrm{C}\right)$ até que não apresentasse grumos. As refeições líquidas eram oferecidas duas vezes ao dia, às 8 e 15h, imediatamente antes das sólidas. Para cada tratamento, foram pesadas as seguintes quantidades de PTS: A, $0 \mathrm{~g}$ (apenas água); B, $120 \mathrm{~g}$; C, $230 \mathrm{~g}$; e D, $350 \mathrm{~g}$.

A PTS apresentava, em sua composição, 2,0\% de umidade, $50,0 \%$ de proteína bruta, $27,6 \%$ de extrato etéreo, 5,6\% de matéria mineral, $0,8 \%$ de fibra bruta e $14,0 \%$ de extrativos não-nitrogenados. Os animais, ao serem desaleitados, tiveram o leite gradativamente substituído pela PTS, de modo a não estranharem a nova alimentação e manterem o reflexo de formação da goteira esofágica. Os concentrados consistiram de milho moído, PTS, uréia em quantidades variáveis e sal mineral. Como único volumoso, foi utilizado o feno de coastcross (Cynodon dactilon), oferecido picado em partes de aproximadamente $10 \mathrm{~cm}$.

Foram colhidas semanalmente amostras do feno e dos concentrados para análises bromatológicas de matéria seca (MS), proteína bruta (PB), extrato etéreo (EE), fibra bruta (FB), fibra em detergente neutro (FDN) e matéria mineral (MM) conforme as normas da AOAC (1980).

Encontram-se, na Tabela 1, as proporções dos ingredientes utilizados e sua composição bromatológica.

O experimento compreendeu quatro sub-períodos de 21 dias cada, dos quais os primeiros 16 foram destinados à adaptação dos animais às dietas. Entre o $17 \underline{0}$ e $20 \underline{\text { o }}$ dia ,foi realizado ensaio de degradabilidade ruminal pela técnica de sacos in situ; no 20 o dia, procedeu-se à coleta de líquido ruminal, para fins analíticos. O consumo de alimentos foi ajustado de forma que as sobras fossem mínimas ou inexistentes.

As variáveis analisadas compreenderam: degradabilidade in situ da MS e PB do farelo de soja e da proteína de soja, e MS e FDN do feno de coastcross; dosagem de ácidos graxos voláteis (acético, propiônico e butírico); dosagem dos níveis de $\mathrm{pH}$ e de $\mathrm{N}-\mathrm{NH}_{3}$; taxa de passagem de líquidos e volume do líquido ruminal. 
Tabela 1 - Proporções de ingredientes nas diferentes dietas e suas composições bromatológicas, com base na matéria seca

Table 1 - Ingredient proportions in the different diets and their chemical composition, in a dry matter basis

\begin{tabular}{|c|c|c|c|c|}
\hline \multirow[b]{2}{*}{$\begin{array}{l}\text { Ingredientes } \\
\text { Ingredients }\end{array}$} & \multicolumn{4}{|c|}{$\begin{array}{l}\text { Porcentagens de proteínas } \\
\text { Protein percents }\end{array}$} \\
\hline & $0 \%$ & $33 \%$ & $66 \%$ & $100 \%$ \\
\hline $\begin{array}{l}\text { Milho (\%) } \\
\text { Corn }\end{array}$ & 79,4 & 85,23 & 90,9 & 96,65 \\
\hline $\begin{array}{l}\text { Prot.text.de soja }(\%) \\
\text { Textured sovbean meal }\end{array}$ & 17,8 & 11,82 & 6,0 & 0,0 \\
\hline $\begin{array}{l}\text { Uréia }(\%) \\
\text { Urea }\end{array}$ & 0,8 & 0,85 & 0,9 & 0,95 \\
\hline $\begin{array}{l}\text { Sal mineral }(\%) \\
\text { Mineral salt }\end{array}$ & 2,0 & 2,1 & 2,2 & 2,4 \\
\hline $\begin{array}{l}\text { Ingredientes } \\
\text { Ingredients }\end{array}$ & $\begin{array}{c}\mathrm{MS}(\%) \\
D M\end{array}$ & $\begin{array}{c}\mathrm{PB}(\%) \\
C P\end{array}$ & $\mathrm{~F}(\%)$ & $\mathrm{EE}(\%)$ \\
\hline $\begin{array}{l}\text { Milho } \\
\text { Corn }\end{array}$ & 86,43 & 9,62 & 9,00 & 4,3 \\
\hline $\begin{array}{l}\text { Feno de coastcross } \\
\text { Coastcross hay }\end{array}$ & 88,40 & 10,60 & 76,2 & 0,65 \\
\hline $\begin{array}{l}\text { Uréia } \\
\text { Urea }\end{array}$ & - & 290,5 & - & - \\
\hline $\begin{array}{l}\text { MS }=\text { matéria seca }(d r y) \\
\text { PB }=\text { proteína bruta }(c \\
\text { FDN }=\text { fibra em deterge } \\
\text { E }=\text { extrato etéreo }( \\
0 \%=\text { zero } \% \text { de prote } \\
0 \%=\text { zero } \% \text { soybean } p\end{array}$ & $\begin{array}{l}\text { y matter). } \\
\text { crude prot } \\
\text { ente neuti } \\
\text { ether extr } \\
\text { eina de } \mathrm{S} \\
\text { rotein in lic }\end{array}$ & $\begin{array}{l}\text { (neutral d } \\
\text { t). } \\
\text { na form }\end{array}$ & $\begin{array}{l}\text { rgent fib } \\
\text { líquida. }\end{array}$ & \\
\hline
\end{tabular}

Para determinação dos ácidos graxos voláteis (AGV), utilizou-se a metodologia preconizada por Erwin et al. (1961). O pH do conteúdo ruminal foi registrado imediatamente após a coleta do material em pontos diferentes do rúmen, empregando-se um potenciômetro digital portátil.

A degradabilidade in situ foi desenvolvida de acordo com Mehrez \& Ørskov (1977), em sacos de náilon, com porosidade de 50 micras, medindo 19 x 10 $\mathrm{cm}$. Os sacos contendo farelo de soja e PTS foram incubados por tempos de 1,$5 ; 3 ; 6 ; 12 ; 24$; e 48 horas e aqueles com feno de coastcross, por $6,12,24,48,72$ e 96 horas. Os sacos destinados a tempos de incubação de $0 \mathrm{~h}$ foram mergulhados em água aquecida a $39^{\circ} \mathrm{C}$, por 5 minutos (Cummins et al., 1983). As análises bromatológicas da MS e da PB foram realizadas segundo normas da AOAC (1980) e as de FDN, segundo Goering \& Van Soest (1970).

Os dados de degradabilidades potencial e efetiva foram ajustados pelo modelo de Ørskov \& McDonald (1979). Determinações de nitrogênio amoniacal $\left(\mathrm{N}^{-\mathrm{NH}_{3}}\right)$ foram realizadas conforme proposto por Foldager (1977).
A determinação do turnover, volume do líquido ruminal e da taxa de passagem de líquido pelo rúmen foi obtida pelo uso de polietilenoglicol de peso molecular 4000 (PEG), seguindo-se o proposto por Hyden (1956).

As análises estatísticas foram realizadas utilizando o Statistical Analysis System (SAS, 1985), considerando-se significativos os níveis de $\mathrm{P}<0,05$.

\section{Resultados e Discussão}

Os consumos de MS obtidos nos tratamentos 0 (zero \% de proteína na forma líquida), 33, 66 e 100\% foram iguais a 4,$48 ; 4,61 ; 4,47$; e 4,62 $\mathrm{kg}$ por animal, durante o período experimental - resultados considerados estatisticamente semelhantes, comprovando que a substituição gradual na forma de fornecer a proteína, de sólida para líquida, tornando-a sobrepassante, não altera o consumo de matéria seca, corroborando os resultados apresentados por Robinson et al. (1976).

Contrariamente, o aumento na ingestão de matéria seca, em ruminantes jovens, quando se utilizam fontes protéicas que sobrepassam o rúmen é relatado por diversos autores (Sampath \& Sivaraman, 1986; Dawson et al., 1988; Guthrie \& Wagner, 1988; Petit et al., 1991; Swartz et al., 1991; Mir et al., 1991; Iriki et al. 1992; Reddy et al., 1993; Maiga et al., 1994; Bunting et al. 1996; Sampath et al., 1996). A explicação para os melhores resultados de consumo e ganhos de peso seria o maior afluxo de aminoácidos essenciais para o intestino delgado, segundo Koeln \& Paterson (1986).

Como não foi encontrada resposta em consumo quando empregadas maiores quantidades de proteínas não degradadas no rúmen, poderiam ser consideradas as possibilidades de queda na síntese de proteína microbiana ruminal, ou da fonte de proteína não degradável ser pobre em aminoácidos essenciais. É reconhecido o fato de a proteína microbiana ser excelente fonte de lisina e metionina, aminoácidos essenciais tidos como limitantes para o crescimento e desenvolvimento de animais jovens (Do Prado et al., 1989; Iriki et al., 1992), enquanto a proteína da soja apresenta deficiência nestes aminoácidos.

Não foram encontrados efeitos das formas sólida ou líquida de administração do suplemento protéico sobre o volume líquido ruminal (Tabela 2), sobre o fluxo líquido diário, ou sobre fluxo líquido diário por quilo de matéria seca consumida $(\mathrm{p}>0,05)$. Porém, a menor concentração de proteína no concentrado provocou decréscimo nas taxas de passagem de 
Tabela 2 - Efeitos da forma de administração do suplemento protéico sobre taxa de passagem de líquidos (TP), turnover (TN) e volume líquido (VL), em relação às porcentagens de proteína de soja presentes nos tratamentos, na forma sólida $(0 \%=$ zero $\%$ de proteína de soja na forma líquida)

Table 2 - Effects of feeding ways of protein supplement over liquid fluid rate (TP), liquid turn over (TN), liquid volume (VL), related to percents of solid soybean concentrations $10 \%=$ zero $\%$ of soybean protein in liquid form)

\begin{tabular}{|c|c|c|c|c|c|c|c|}
\hline & \multicolumn{4}{|c|}{$\begin{array}{l}\text { Porcentagens de proteínas } \\
\text { Protein percents }\end{array}$} & \multirow[b]{2}{*}{$\begin{array}{l}\text { Média } \\
\text { Mean }\end{array}$} & \multirow[b]{2}{*}{$\begin{array}{c}\text { Coeficiente de variação } \\
\text { Coefficient of variation }\end{array}$} & \multirow[b]{2}{*}{$\begin{array}{c}\text { p.linearidade } \\
\text { p.linearity }\end{array}$} \\
\hline & 0 & 33 & 66 & 100 & & & \\
\hline$\overline{\mathrm{TP}}$ & 10,98 & 7,01 & 7,27 & 7,28 & 8,14 & 35,8 & $0,0457(*)$ \\
\hline $\mathrm{TN}$ & 2,64 & 1,70 & 1,75 & 1,75 & 1,96 & 35,6 & $0,0463(*)$ \\
\hline L & 22,18 & 22,13 & 22,36 & 21,47 & 22,04 & 37,8 & 0,6329 \\
\hline
\end{tabular}

líquidos e de turnover ruminal. Entre os fatores tidos como modificadores do movimento de líquidos no interior do rúmen podem ser apontados a relação concentrado/volumoso, o nível de ingestão da dieta e sua composição química (Lallès \& Poncet, 1990). A maior relação concentrado/volumoso na dieta pode ocasionar redução no trânsito de líquidos pelo rúmen, conforme relatado por Huntington et al. (1981), Rode et al. (1985), Ledoux et al. (1985) e Bartocci et al. (1997), sendo que estes últimos autores relatam ainda tempo de retenção médio maior para a ração com maior quantidade de concentrado. Peters et al. (1990), no entanto, não encontraram diferenças na taxa de diluição de conteúdos do rúmen de novilhos alimentados com alta porcentagem de volumoso ou de concentrado.

Considerando-se que o presente experimento forneceu menores porções de concentrado à medida que se fez transferência da proteína da forma sólida para líquida, foi observada maior taxa de passagem e maior turnover nos animais do tratamento com porcentagem mais alta de concentrado. Entretanto, as diferenças entre as proporções concentrado/volumoso foram muito pequenas, variando entre 72/28 e 67/33.

A composição química da dieta apresentou resultados coerentes com os de vários autores que relatam aumento no fluxo de líquidos no rúmen como resultado da maior quantidade de proteína (McCollum \& Galyean, 1985; Caton et al., 1988; Njoya, 1997). Ørskov et al. (1986) e Lopez et al. (1994) registraram alta correlação entre pressão osmótica, volume ruminal e fluxo de líquidos neste órgão. Carter \& Grovum (1990) constataram maior consumo voluntário de água em ovinos submetidos a modificações na osmolaridade ruminal, sugerindo mediação da sede através de receptores localizados na mucosa daquele órgão. Bunting et al. (1989) também encontraram maior consumo voluntário de água em bezerros recebendo dieta com alto nível de proteína.

Não houve aumento na ingestão de alimentos, fator que poderia justificar incremento no fluxo de líquidos. Como as proteínas provavelmente modificam a osmolaridade ruminal, presume-se que a maior taxa de passagem e turnover encontrados nos tratamentos que apresentaram maior porcentagem da PTS na forma sólida sejam conseqüência do aumento dessa osmolaridade.

A mensuração dos valores de $\mathrm{pH}$ do líquido ruminal não comprovou efeito da forma de administração sólida ou líquida do suplemento protéico. As médias para os valores encontrados nos tempos de colheita $0 \mathrm{~h}, 1 \mathrm{~h}, 3 \mathrm{~h}, 6 \mathrm{~h}, 9 \mathrm{~h}, 12 \mathrm{~h}$ e $24 \mathrm{~h}$. após a primeira refeição foram respectivamente, 5,10; 6,$07 ; 6,28$ e 6,20 , para os tratamentos $0,33,66$ e $100 \%$ de proteína de soja na forma líquida. Em nenhum dos tempos de coleta foi encontrada qualquer diferença entre tratamentos. Estes resultados estão de acordo com os de Guthrie \& Wagner (1988), Klusmeyer et al. (1990), Newboldt \& Rust (1990), Freeman et al. (1992) e O’Mara et al. (1998), mas divergem dos relatos de Albro et al. (1993) e Bowers et al. (1965), que evidenciaram alterações no pH do conteúdo do rúmen de animais recebendo diferentes fontes protéicas, com diversos teores de degradabilidade ruminal.

Os efeitos da via de administração de suplemento protéico sobre os valores dos ácidos graxos voláteis $(\mathrm{AGV})$ totais $(\mathrm{C} 2+\mathrm{C} 3+\mathrm{C} 4)$ e as proporções molares de propionato (C3) estão expostos na Tabela 3. Para o total de $\operatorname{AGV}(\mathrm{C} 2+\mathrm{C} 3+\mathrm{C} 4)$, não houve efeito significativo da via de administração. Para as proporções molares de ácido propiônico (C3), observou-se queda linear, à medida que os suplementos foram administrados em maior proporção na forma

R. Bras. Zootec., v.33, n.6, p.1888-1896, 2004 (Supl. 1) 
líquida seis horas após a refeição. As proporções molares de ácido acético (C2) apresentaram queda linear e as de acido butírico (C4), aumento linear de acordo com o tempo passado após a refeição.

Os efeitos dos tratamentos sobre os valores dos ácidos acético e butírico não tiveram significância estatística (Tabela 4).

Os resultados obtidos concordam com Newbold \& Rust (1990), Klusmeyer (1990), Chester-Jones et al. (1991), Albro et al. (1993) e O’Mara et al. (1998), que trabalharam com fontes protéicas de diferentes degradabilidades no rúmen, não observando diferenças nas medidas de AGV totais. Diferem, no entanto, das observações de Nocek et al (1984) e Abdelgadir et al. (1996), que acusaram aumento na concentração de AGVs totais e alterações nas porcentagens molares de acetato e de butirato. Chiou et al. (1997) observaram efeito da fonte de proteína sobre a concentração dos AGVs totais, e alterações nas porcentagens molares de ácidos isolados, conforme a fonte protéica utilizada.
Segundo Nocek et al (1984) o maior aporte de matéria orgânica, resultante do aumento na proporção de proteína dietética altamente degradável, acarretaria maior produção de AGVs. No presente experimento, os tratamentos com 100 e $66 \%$ da PTS administrada via concentrado apresentaram alta quantidade de proteína degradável no rúmen, o que poderia ocasionar maior produção de $\mathrm{AGV}$. Este resultado foi observado apenas em relação à porcentagem molar do ácido propiônico, no horário de 6 horas pós-refeição. Houve aumento na taxa de passagem da fração líquida quando os animais receberam o suplemento protéico na forma sólida, via concentrado, o que, possivelmente, foi efeito da maior ingestão de água decorrente do aumento da osmolaridade e/ou aumento da diurese provocado pela necessidade de eliminação da uréia sangüínea. Meng et al. (1999) observaram que o aumento no fluxo de líquidos causa diminuição na concentração total de AGVs, pois estes sofrem arraste em direção ao abomaso. Há possibilidade de ter ocorrido aumento na produção de AGVs nos animais

Tabela 3 - Efeitos da forma de administração de suplemento protéico sobre as concentrações de ácidos graxos totais e sobre as concentrações molares de ácido propiônico, em relação às porcentagens de proteína de soja na forma líquida

Table 3 - Effects of feeding forms of protein supllement over total volatily fatty acid concentrations, and over molar concentrations of propionic acid related to soybeean protein percentages in liquid form

Ácidos acético, propiônico e butírico

Acetic, propionic and butiric acids

\begin{tabular}{|c|c|c|c|c|c|c|}
\hline & \multicolumn{4}{|c|}{$\begin{array}{c}\text { Porcentagens de proteínas } \\
\text { Protein percents }\end{array}$} & \multirow[b]{2}{*}{$\begin{array}{c}\text { Coeficiente de variação } \\
\text { Coefficient of variation }\end{array}$} & \multirow[b]{2}{*}{$\begin{array}{l}\text { p.linearidade } \\
\text { p.linearity }\end{array}$} \\
\hline & 0 & 33 & 66 & 100 & & \\
\hline \multicolumn{7}{|c|}{ Tempo/Trat. } \\
\hline 0 & 76,61 & 76,70 & 48,49 & 59,27 & 43,30 & 0,1836 \\
\hline 2 & 64,56 & 72,90 & 59,45 & 67,57 & 23,06 & 0,9035 \\
\hline 3 & 69,55 & 60,98 & 64,90 & 56,30 & 30,73 & 0,2704 \\
\hline 4 & 70,20 & 63,85 & 72,41 & 62,37 & 39,92 & 0,6988 \\
\hline 5 & 75,00 & 75,32 & 84,31 & 71,08 & 23,39 & 0,9331 \\
\hline 6 & 84,27 & 72,36 & 77,08 & 61,18 & 23,02 & 0,1765 \\
\hline & \multicolumn{6}{|c|}{$\begin{array}{l}\text { Ácido propiônico } \\
\text { Propionic acid }\end{array}$} \\
\hline 0 & 32,23 & 33,40 & 25,64 & 22,67 & 51,11 & 0,1307 \\
\hline 2 & 33,67 & 32,49 & 27,99 & 27,41 & 46,23 & 0,1435 \\
\hline 3 & 34,24 & 32,85 & 27,58 & 24,99 & 49,74 & 0,1756 \\
\hline 4 & 35,78 & 32,35 & 27,50 & 25,36 & 48,74 & 0,1496 \\
\hline 5 & 35,38 & 33,31 & 27,96 & 25,22 & 46,76 & 0,0951 \\
\hline 6 & 39,14 & 33,29 & 27,76 & 25,09 & 48,75 & 0,0443 \\
\hline
\end{tabular}

$0 \%=$ zero $\%$ de proteína de soja na forma líquida (zero \% soybean protein in liquid form).

$\mathrm{p}$ linear $=$ probabilidade de linearidade (linear probability)

R. Bras. Zootec., v.33, n.6, p.1888-1896, 2004 (Supl. 1) 
Tabela 4 - Efeitos da forma de administração de suplemento protéico sobre as porcentagens molares de ácidos acético e butírico, em relação às porcentagens de proteína de soja na forma líquida

Table 4 - Effects of feeding way of protein supplement on molar concentrations of acetic and butyric acids, related to soybean percentage in liquid form

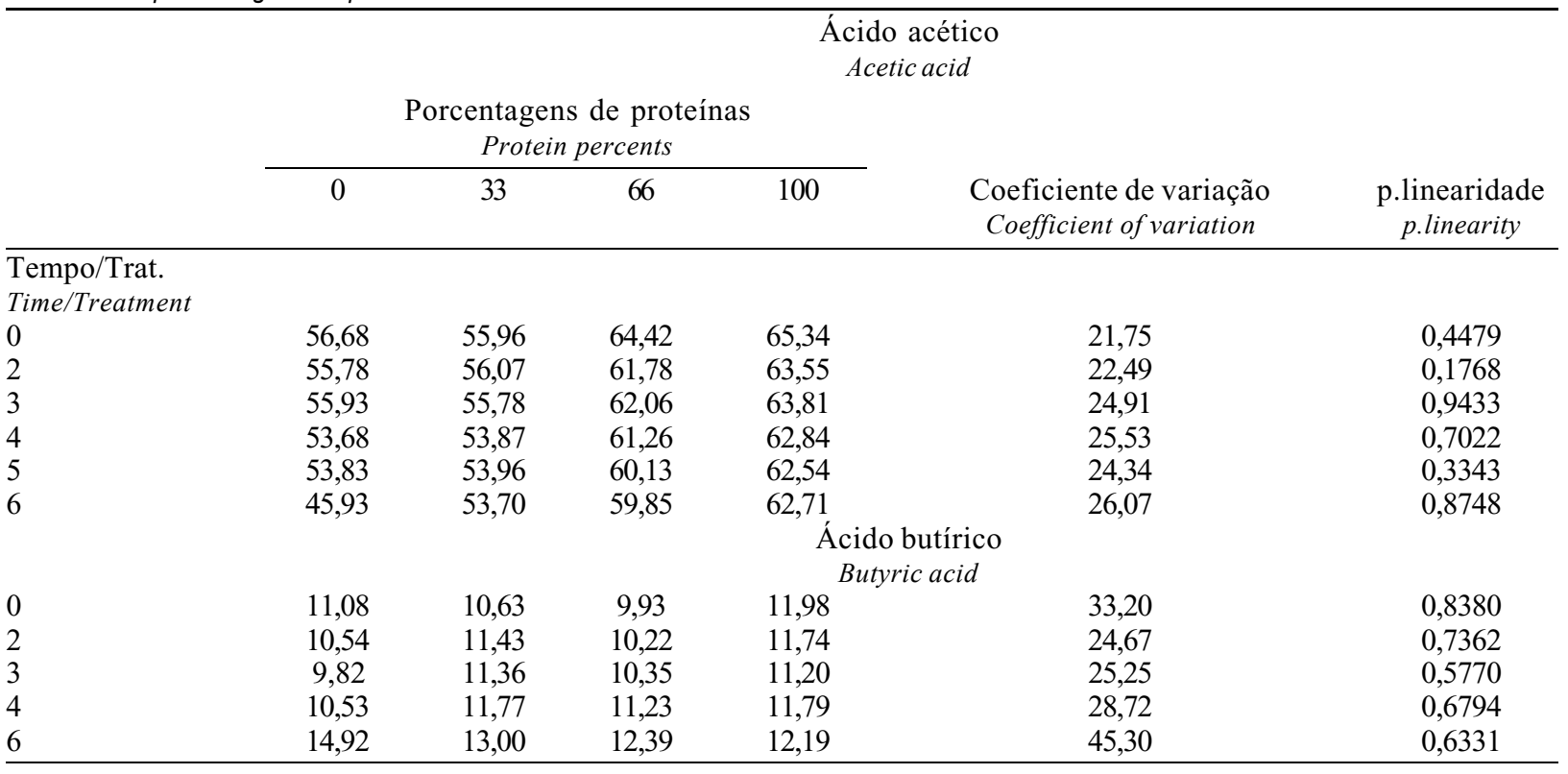

$0 \%=$ zero $\%$ de proteína de soja na forma líquida (zero \% soybean protein in liquid form).

$\mathrm{p}$ linear $=$ probabilidade de linearidade (linear probability)

Tabela 5 - Efeitos da forma de administração do suplemento protéico sobre a degradabilidade efetiva da MS e PB da proteína bruta do farelo de soja, da proteína bruta da PTS, da MS e FDN do feno (porcentagens, $r=0,02$ )

Table 5 - Effects of feeding way of protein supplement on effective degradability of soybean meal dry matter (DM) and crude protein (CP), STP crude protein, hay dry matter and hay neutral detergent fiber (NDF) (percents, $r=.02$ )

\begin{tabular}{|c|c|c|c|c|c|c|}
\hline & \multicolumn{4}{|c|}{$\begin{array}{c}\text { Porcentagens de proteínas } \\
\text { Protein percent }\end{array}$} & \multirow[b]{2}{*}{$\begin{array}{c}\text { Coeficiente de variação } \\
\text { Coefficient of variation }\end{array}$} & \multirow[b]{2}{*}{$\begin{array}{l}\text { p.linearidade } \\
\text { p.linearity }\end{array}$} \\
\hline & 0 & 33 & 66 & 100 & & \\
\hline MS.F.SOJA & 77,64 & 80,67 & 80,85 & 78,07 & 12,7 & 0,8659 \\
\hline $\begin{array}{l}\text { Dry matter soybean meal } \\
\text { PB.F.SOJA }\end{array}$ & 78,07 & 77,77 & 77,28 & 74,18 & 21,5 & 0,1241 \\
\hline $\begin{array}{l}\text { Crude protein soybean meal } \\
\text { PB PTS } \\
\text { Crude protein PTS }\end{array}$ & 82,29 & 81,98 & 85,86 & 87,68 & 5,1 & 0,1917 \\
\hline $\begin{array}{l}\text { MS FENO } \\
\text { Hay dry matter }\end{array}$ & 34,44 & 34,50 & 37,41 & 33,56 & 13,1 & 0,9712 \\
\hline $\begin{array}{l}\text { FDN FENO } \\
\text { Hay NDF }\end{array}$ & 33,68 & 35,99 & 35,05 & 34,22 & 13,8 & 0,8773 \\
\hline
\end{tabular}

$0 \%$ = zero \% de proteína de soja na forma líquida (zero \% soybean protein in liquid form).

$\mathrm{p}$ linear $=$ probabilidade de linearidade (linear probability).

que receberam os tratamentos contendo maior quantidade de proteína no concentrado e este aumento não ter sido registrado em decorrência do menor tempo de permanência no rúmen, graças às maiores taxas de passagem da fase líquida.
Não houve efeito significativo na degradabilidade potencial e efetiva da MS e da PB tanto do farelo de soja quanto da PTS nos diversos tempos de incubação e para os diferentes tratamentos que variaram as quantidades de proteína ingressando no rúmen. Este

R. Bras. Zootec., v.33, n.6, p.1888-1896, 2004 (Supl. 1) 
fato foi registrado tanto em termos de degradabilidade potencial como degradabilidade efetiva, utilizando-se as estimativas para taxas de passagem de 0,$02 ; 0,04 \mathrm{e}$ 0,06 . Não houve diferenças nas taxas de degradabilidade ruminal da PB entre PTS e farelo de soja. Os resultados de degradabilidade da MS e PB obtidos neste experimento concordam com os relatados por Lodoño Hernandez et al. (1998).

A falta de resposta observada no desaparecimento ruminal da MS e de PB de amostras de fontes protéicas quando foram modificadas as circunstâncias do ingresso da proteína no rúmen (quantidade ou degradabilidade), no presente estudo, não é compartilhada pelo trabalho de Freeman et al. (1992), que relataram, ao fornecer a novilhos suplementação diferindo na porcentagem de proteína (43 e $22 \%$ de proteína), que o desaparecimento de nitrogênio da amostra foi maior para a dieta mais rica em proteína.

As variações encontradas na degradabilidade ruminal da MS e da PB de amostras de alimentos utilizando-se a técnica dos sacos de nylon in situ podem ter como causas o nível de consumo, a relação volumoso/concentrado, a composição da dieta e a freqüência de alimentação (Nocek et al., 1979; Loerch et al., 1983; Eliman \& Ørskov, 1984). Estes fatores afetam as características do líquido ruminal, como o $\mathrm{pH}$, que altera a solubilidade da proteína interferindo em seu ponto isoelétrico, determinando maior ou menor repulsão entre as moléculas (Loerch et al., 1983) e a taxa de passagem, que, se aumentada, promove maior arraste de material a ser degradado, especialmente aquele de alta solubilidade (Colucci et al., 1982; Eliman \& Ørskov, 1984; Kirkpatrick \& Kennelly, 1987).

Os dados referentes às alterações na degradabilidade in situ da matéria seca (MS) e fibra em detergente neutro (FDN) do feno de coastcross, como resultado da substituição gradativa da PTS do concentrado para o suplemento líquido, são apresentados na Tabela 5.

Não houve efeito da variação da forma de administração da fonte protéica, sólida ou líquida, sobre a degradabilidade potencial ou efetiva da MS e FDN do feno de coastcross, concordando com Petit \& Flipot (1992), Sefrin et al. (1997), Queiroz et al. (1998) Klusmeyer et al. (1990) e Sultan et al. (1992). A quantidade de proteína dietética, contudo, parece alterar a degradabilidade da fibra. Freeman et al. (1992), comparando dietas com 43 e 22\% de proteína, observaram maior desaparecimento ruminal da FDN e MS com o maior nível protéico.
A necessidade de nitrogênio para o metabolismo das bactérias ruminais também afeta a degradação da fibra, sendo que o mínimo requerido para seu crescimento normal foi de 5,0 mg/dL (Satter \& Slyter, 1974), embora outros autores tenham assegurado que a concentração para a máxima degradação da fibra deve chegar a 21,4 mg/dL (Hume et al., 1970) ou 23,0 mg/dL (Mehrez et al., 1977). No presente experimento, verificou-se que as concentrações de $\mathrm{N}$ amoniacal atingiram, nos tratamentos com maior quantidade de proteína ingressando no rúmen, o máximo de $15,18 \mathrm{mg} / \mathrm{dL}$, valor que não atinge as concentrações consideradas ótimas para máxima digestão da fibra, sendo esta talvez uma das razões para a falta de resposta observada na degradabilidade ruminal da FDN e MS do feno nas dietas com maior quantidade de proteína oferecida via concentrado.

\section{Conclusões}

A administração de proteína texturizada de soja na forma líquida não deve ser recomendada com a finalidade de se obter alterações no consumo de matéria seca ou nos diferentes parâmetros indicadores de fermentação ruminal: $\mathrm{pH}$, concentrações de ácidos graxos voláteis, degradabilidade de alimentos e cinética da fase líquida.

\section{Literatura Citada}

ABDELGADIR, I.E.O.; MORRIL, J.L.; HIGGINS, J.J. Ruminal avaiabilities of protein and starch: effects on growth and ruminal and plasma metabolites of dairy calves. Journal of Dairy Science, v.79, n.2, p.283-290, 1996.

ALBRO, J.D.; WEBER, D.W.; DelCURTO, T. Comparison of whole, raw soybeans, extruded soybeans, soybean meal and barley on digestive characteristics and performance of weaned beef steers consuming mature grass hay. Journal of Animal Science, v.71, p.26-32, 1993.

ASSOCIATION OF ANALYTICAL CHEMISTS - AOAC. Official methods of analyses. 10.ed., Washington, D.C.: 1980.

BARTOCCI, S.; AMICI, A.; VERNA, M. et al. Solid and fluid passage rate in buffalo, cattle, and sheep fed diets with different forage to concentrate ratios. Livestock Production Science, v.52, p.201-208, 1997.

BOWERS, H.B.; PRESTON, T.R.; McLEOD, N.A et al. Intensive beef production. 5. The effect of diferent sources of protein on nitrogen retention. Animal Production, v.7, p.303-309, 1965.

BUNTING, L.D.; BOLING, J.A.; MacKOWN, C.T. Effect of dietary protein level on nitrogen metabolism in the growing bovine: 1. Nitrogen recycling and intestinal protein supply in calves. Journal of Animal Science, v.67, p.810-819, 1989.

BUNTING, L.D.; FERNANDEZ, J.M.; FORNEA, R.J.et al Seasonal effects of supplemental fat or undegradable protein

R. Bras. Zootec., v.33, n.6, p.1888-1896, 2004 (Supl. 1) 
on the grouwth and metabolism of Holstein calves. Journal of Dairy Science, v.79, n.9, p.1611-1620, 1996.

CARTER, R.R.; GROVUM, W.L. Factors affecting the voluntary intake by sheep. 5. The inhibitory effect of hypertonicity in the rumen. British Journal of Nutrition, v.64, p.285-299, 1990 .

CATON, J.S.; FREEMAN, A.S.; GALYEAN, M.L. Influence of protein supplementation on forage intake, in situ forage disappearence, ruminal fermentation, and digesta passage rates in steers grazing dormant blue grama rangeland. Journal of Animal Science, v.66, p.2262-2271, 1988.

CHESTER-JONES, H.; STERN, M.D.; METWALLY, H.M.eet al. Effects of dietary protein-energy interrelationships on Holstein steer performance and ruminal bacterial fermentation in continuous culture. Journal of Animal Science, v.69, n.12, p.4956-4966, 1991

CHIOU, P.W.S.; YU, B.; WU, S.S. et al . Effect of dietary protein source on performances and rumen characteristics of dairy cows. Animal Feed Science and Technology, v.68, p.339-351, 1997.

COLUCCI, P.E.; CHASE, L.E.; Van SOEST, P.J. Feed intake, apparent diet digestibility, and rate of particulate passage in dairy cattle. Journal of Dairy Science, v.65, p. 1445 $1456,1982$.

CUMMINS, K.A.; NOCEK, J.E.; POLAN, C.E. et al Nitrogen degradability and microbial protein syntesis in calves fed diets of varing degradability by the bag technique. Journal of Dairy Science, v.66, n.11, p.2356-2364, 1983.

DAWSON, D.P.; MORRIL, J.L.; REDDY, P.G. et al . Soy protein concentrate and heated soy flours as protein sources in milk replacer for preruminant calves. Journal of Dairy Science, v.71, n.5, 1301-1309, 1988.

DO PRADO, I.N.; TOULLEC, R.; GUILlOTEAU, P. et al . Digestion des protèines de pois et de soja chez le veau préruminant. II. Digestibilité apparente à la fin de l'ileon et du tube digestif. Reproduction, Nutrition, Dévelopement, v.29, 425-439, 1989 .

ELIMAN, M.E.; ØRSKOV, E.R. Factors affecting the outflow of protein supplements from the rumen. 1. Feeding level. Animal Production, v.38, p.45-51, 1984.

ERWIN, E.S.; MARCO, G.J.; EMERY, E.M. Volatile fatty acids analyses of blood and rumen fluid by gas chromatography. Journal of Dairy Science, v.44, n.9, p.654-660, 1961.

FOLDAGER, J. Protein requirement and non protein nitrogen for high producing cows in early lactation. $\mathrm{PhD}$. Thesis, East Leasing - Michigan State Univarsity, 1977.

FREEMAN, A.S.; GALYEAN, M.L.; CATON, J.S. Effects of suplemental protein percentage and feeding level on intake, ruminal fermentation, and digesta passage in beef steers fed prairie hay. Journal of Animal Science, v.70, p.1562$1572,1992$.

GOERING, H.K.; Van SOEST, P.J. Forage fiber analysis (apparatus, reagents, procedures and some applications). Agriculture Handbook, 379, Agricultural Research Service, Washington D.C., 19 p., 1970.

GUTHRIE, M.J.; WAGNER, D.G. Influence of protein or grain supplementation and increasing levels of soybean meal on intake, utilization, and passage rate of prairie hay in beef steers and heifers. Journal of Animal Science, v.66, p.1529-1537, 1988.

HUME, I.D.; MOIR, R.J.; SOMERS, M. Synthesis of microbial protein in the rumen. I. Influence of the level of nitrogen intake. Australian Journal of Agricultural Research, v. 21, p. 283,1970

HUNTINGTON, G.B.; BRITTON, R.A.; PRIOR, R.L. Feed intake, rumen fluid volume, and turnover, nitrogen, and mineral balance and acid-base status of whethers changed from low to high concentrate diets. Journal of Animal Science, v.52, p.1376-1317, 1981.

HYDEN, S. A turbidometric method for the determination of higher polyetylene glycols in biological materials. Kunkliga Lantbruks Hogskolans Annaler., v.22, p.139-145, 1956.

IRIKI, T.; ADACHI, K; ABE, M. Necessity of ruminaly undegraded dietary protein in 4-5 months-old calves under the condition of low-protein intake. Animal Science and Technology, v.64, n.4, p.414-419, 1992.

KIRKPATRICK, B.K.; KENNELLY, J.J. In situ degradability of protein and dry matter from single protein sources and from a total diet. Journal of Animal Science, v.65, p567576, 1987.

KLUSMEYER, T.H.; McCARTHY, Jr., R.D.; CLARK, J.H. et al. Effects of source and amout of protein on ruminal fermentation and passage of nutrients to the small intestine of lactating cows. Journal of Dairy Science, v.73, n.12, p.3526-3537, 1990.

KOELN, L.L.; PATERSON, J.A. Nitrogen balance and amino acid disappearence from the small intestine in calves fed soybean meal, toasted soybean meal, or corn gluten meal supplemented diets. Journal of Animal Science, v.63, p.1258-1266, 1986.

LALLÈS, J.P.; PONCET, C. Rate of passage of digesta during and after weaning in calves fed concentrate diets containing pea or soya-bean meal. Livestock Production Science, v.24, p.333-345, 1990.

LEDOUX, D.R.; WILLIAMS, J.E.; STROUD, T.E. et al Influence of forage level on passage rate, digestibility, and performance of cattle. Journal of Animal Science, v.61, n.6, p.1559-1566, 1985.

LODOÑO HERNÁNDEZ, F.I.; SANCHEZ, L.M.B.; VIEIRA, R.A.M. et al. Desaparecimento ruminal e digestibilidade intestinal e total da matéria seca e proteína bruta de alguns suplementos concentrados. Revista Brasileira de Zootecnia, v.27, n.4, p.777-782, 1998.

LOERCH, S.C.; BERGER, L.L.; GIANOLA, D. et al. Effects of dietary protein source and energy level on in situ nitrogen disappearence of various protein sources. Journal of Animal Science, v.56, p.206-216, 1983.

LÓPEZ, S.; HOVELL, F.D.B.; MacLEOD, N.A. Osmotic pressure, water kinetics, and volatile fatty acids absoption in tha rumen of sheep sustained by intragastric infusions. British Journal of Nutrition, v.71, p.153-168, 1994.

LUCCI, C.S.; SCHALCH, E.; NOGUEIRA FILHO, J.C.M. et al Fenos de capim Rhodes (Chloris gayana) ou de alfafa (Medicago sativa) em dietas com dois níveis protéicos. II. Degradação de nutrientes no rúmen. Revista da Faculdade de Medicina Veterinária e Zootecnia da Universidade de São Paulo, v.26, n.2, p.267-274, 1989.

MAIGA, H.A.; SCHINGOETHE, D.J.; LUDENS, F.C. et al Response of calves to diets that varied in amounts of ruminaly degradable carbohydrates and protein. Journal of Dairy Science, v.77, p.278-283, 1994.

McALLAN, A.B.; SMITH, R.H. Factors influencing the digestion of dietary carbohydrates between the mouth and abomasum of steers. British Journal of Nutrition, v. 50, p.445-454, 1983. 
McCOLLUM, F.T.; GALYEAN, M.L. Influence of cottonseed meal suplementation on voluntary intake, rumen fermentation, and rate of passage of prairie hay in beef steers. Journal of Animal Science, v.60, p.570, 1985.

MEHREZ, A.Z.; ØRSKOV, E.R. A study of the artificial fibre bag technique for determining the digestibility of feeds in the rumen. Journal of Agricultural Science, v.88, n.3, p.437-443, 1977.

MEHREZ, A.Z.; ØRSKOV, E.R.; McDONALD, I. Rates of rumen fermentation in relation to ammonia concentration. British Journal of Nutrition, v.38, n.3, p.437-443, 1977.

MENG, Q.; KERLEY, M.S.; LUDDEN, P.A. et al Fermentation substrate and dilution rate interact to affect microbial growth and effeiciency. Journal of Animal Science, v.77, p.206-214, 1999.

MIR, P.S; BURTON, J.H; BUCHANAN-SMITH, J.G. Nutritional performance of calves fed milk replacers containing processed soybean products. Canadian Journal of Animal Science, v.71, p.97-106, 1991.

NEWBOLD, J.R.; RUST, S.R. Effect of protein degradability and source on rumen function, food intake, and growth in holstein cattle given high-moisture maize grain. Animal Production, v.50, p.399-408, 1990.

NJOYA, A. Protein supplementation of grazing cattle in the semi-arid zone of Cameroon. Tropical Animal Health and Production, v.29, n.4, p. 193-200, 1997.

NOCEK, J.E.; CUMMMINS, K.A.; POLAN, C.E. Ruminal disappearence of crude protein and dry matter in feeds and combined effects in formulated rations. Journal of Dairy Science, v.62, p.1587-1598, 1979.

NOCEK, J.E.; HEALD, C.W.; POLAN, C.E. Influence of ration physical form and nitrogen availability on ruminal morphology of growing bull calves. Journal of Dairy Science, v.67, p.334-343, 1984

O'MARA, F.P.; MURPHY, J.J.; RATH, M. Effect of amout of dietary supplement and source of protein on milk production, ruminal fermantation, and nutrient flows in dairy cows. Journal of Dairy Science, v.81, n.9, p.2430-2439, 1998.

ØRSKOV, E.R.; BENZIE, D.; KAY, R.N.B. The effects of feeding procedure on closure of the oesophageal groove in young sheep. British Journal of Nutrition, v.24, p.785$795,1970$.

ØRSKOV, E.R.; FRASER, C.; CORSE, E.L. The effect on protein utilization of feeding different protein suplements via the rumen or via the abomasum in young growing sheep. British Journal of Nutrition, v.24, p.803-809, 1970.

$\varnothing \mathrm{RSKOV}$, E.R.; McDONALD, I. The estimation of protein degradability in the rumen from incubation measurements weighted according to rate of passage. Journal of Agricultural Science, v.92, p.499-503, 1979.

$\varnothing$ RSKOV, E.R.; MACLEOD, N.A.; KYLE, D.J. Flow of nitrogen from the rumen and abomasum in cattle and sheep given protein-free nutrients by intragastric infusion. British Journal of Nutrition, v.56, p.241-248, 1986.

PETERS, J.P.; PAULISSEN, J.B.; ROBINSON, J.A. The effects of diet on water flux and volatile fatty acids concentrations in the rumen of growing beef steers fed once daily. Journal of Animal Science, v.68, p.1711-1718, 1990.

PETIT, H.V.; FLIPOT, P.M. Feed utilization of beef steers fed grass as hay or silage with or without nitrogen supplementation. Journal of Animal Science, v.70, n.3, p.876-883, 1992.

PETIT, H.V.; LACHANCE, B.; DIORIO, D. The effect of protein source on the growth and carcass characteristics of veal calves. Canadian Journal of Animal Science, v.71, n.2, p.409-416, 1991

R. Bras. Zootec., v.33, n.6, p.1888-1896, 2004 (Supl. 1)
PIMENTEL GOMES, F. Curso de estatística experimental. Piracicaba: Escola Superior de Agricultura Luiz de Queiroz, 1985. 467p.

QUEIROZ, A.C.; BARBOSA, M.A.; RESENDE, F.D. et al. Suplementação da palhada de milho na alimentação de bovinos. 1. Consumo, taxa de passagem da matéria seca, degradação in situ da matéria seca e fibra em detergente neutro. Revista Brasileira de Zootecnia, v.27, n.2, p.381-389, 1998.

REDDY, P.V.; MORRILL, J.L.; BATES, L.S. Effect of roasting temperatures on soybean utilization by young dairy calves. Journal of Dairy Science, v.76, n.5, p.1387-1393, 1993.

RITTENHOUSE, L.R.; CLANTON, D.C.; STREETER, C.L. Intake and digestibility of winter-range forage by cattle with and without supplements. Journal of Animal Science, v.31, p.1215-1221, 1970 .

ROBINSON, P.H.; MOWAT, D.N.; PARKINS, J.J. et al Reticular groove closure for protein supplementation of calves. Canadian Journal of Animal Science, v. 56 (suplemento), n.4, p. 839, 1976.

RODE, L.M.; WEAKLEY, D.C.; SATTER, L.D. Effect of forage amount and particle size in diets of lactating dairy cows on site of digestion and microbial protein synthesis. Canadian Journal of Animal Science, v.65, p.101-111, 1985.

SAMPATH, K.T.; SIVARAMAN, E. Effect of feeding rations with different levels of rumen degradable protein on growth and digestibility of nutrients in crossbred calves. Kerala Journal of Veterinary Science, v.17 n.2 p. 8-14, 1986.

SAMPATH, K.T.; PRASAD, C.S.; SUNDARESHAN, K. et al . Effect of feeding two levels of undegradable dietary protein (UDP) on growth and nutrient utilization in crossbred female calves. Indian Journal of Animal Nutrition, v.13, n.1, p.1-6, 1996.

STATISTICAL ANALYSES SYSTEM - SAS. SAS User's guide: statistics. 5.ed. Cary: 1985.

SATTER, L.D.; SLYTER, L.L. Effect of ammonia concentration on rumen microbial protein production in vitro. British Journal of Nutrition, v.32, p.199-208, 1974.

SEFRIN, A.R.; LUCCI, C.S.; MELOTTI, L. Degradabilidade ruminal do farelo de soja e do feno de Coast-cross com bovinos fistulados em dietas com diferentes proporções volumoso:concentrado. Brazilian Journal of Veterinary Research and Animal Science, v.34, n.1, p.31-36, 1997.

SULTAN, J.I.; FLUHARTY, F.L.; FIRKINS, J.L. et al . Effects of supplemental protein source and alkaline hydrogen peroxide treatment of wheat straw on site of nutrient digestion and flow of nitrogenous compouds to the duodenum of steers. Journal of Animal Science, v.70, p.3909-3915, 1992.

SWARTZ, L.A; HEINRICHS, A.J.; VARGA, G.A. et al Effect of varying dietary undegradable protein on dry matter intake, growth, and carcass composition of Holstein calves. Journal of Dairy Science, v.74, n.11, p.3884-3891, 1991.

Van GYLSWIK, N.O. The effect of supplementing a low protein hay on the celulolytic bacteria in the rumen of sheep and on the digestibility of cellulose and hemicellulose. Journal of Agricultural Science, v.74, p.169-180, 1970.

WIEDMEIER, R.D.; MALES, J.R.; GASKINS, C.T. Effect of dietary crude protein on the dry matter digestibility of wheat straw diets in cattle. Journal of Animal Science, v. 57, p.1568-1575, 1983.
Recebido em: 09/01/03 Aceito em: 25/03/04 